\title{
$\mathscr{D a s}$ Eiteratur $=\mathscr{A} \mathfrak{r} \mathfrak{d} \mathfrak{i v}$
}

\author{
Betæffentlidungen

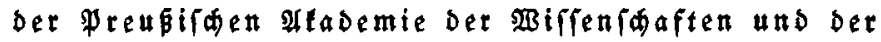 \\ Siteratur= Irdiv: Befellidaft \\ in Berlin
}

Fânfter $\mathfrak{B a n d}$

Berlin und feipfig 1937

\section{Walter de $\mathfrak{G r u ̈ b t e r ~ \& ~} \mathfrak{C}_{\mathfrak{o}}$.}

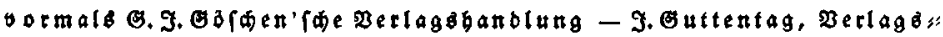

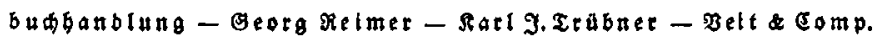




\title{
Briefwediel
}

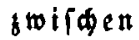 \\ Rarl Wüllenboff und Willbelm Sderer}

\author{
Sm Hufteg oer Peubifden Afabemie ber Wiffenfdaften \\ berangegeben \\ bon
}

Plbert Leikmann

Mit einer Einfübrung

von Cowarb Eardoer

Berlin unb Retpgig 1937

Walter De Grü̈ter \& Co.

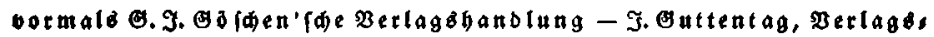
Бйbablung-Georg Retmer - Rarl I. Trábner-Bett \& Eomp. 
Pechiof Pt. 452936

Orue voil Malter be Brunter $\&$ Eo., Betlln $2 \mathbb{3 5}$

Printed in Germany 
frau Marie Sdjerer

zur erinnerung des 6. augu $1 / 1886$ 